\title{
Risk of smoking relapse with the use of electronic cigarettes: A systematic review with meta-analysis of longitudinal studies
}

Laura A. Barufaldi', Renata L. Guerra ${ }^{1}$, Rita de Cássia R. de Albuquerque ${ }^{1}$, Aline Nascimento', Raphael D. Chança ${ }^{1}$, Mirian C. de Souza', Liz M. de Almeida ${ }^{3}$

\begin{abstract}
INTRODUCTION The use of e-cigarettes has been the subject of a public health debate on their possibility of undermining efforts for tobacco control. The aim of this study was to synthesize the risk of smoking relapse with the use of e-cigarettes by former smokers.

METHods MEDLINE, EMBASE, PsycInfo and LILACS were searched without restriction to language or date of publication. Longitudinal observational studies evaluating the association between e-cigarette use and smoking relapse were selected by two independent reviewers, and disagreements solved by discussion with a third researcher. Data extraction and risk of bias assessment were also carried out by two independent reviewers. The meta-analysis was performed using the random effect Mantel-Haenszel model.

RESULTS From 632 retrieved records, six studies were eligible and described, while three were included in the quantitative synthesis. The studies were conducted in the USA, UK and France, with final sample size varying from 374 to 4094 former smokers. Risk of relapse was 2.03 (95\% CI: 1.39-2.96) among former smoker users than non-users of e-cigarettes, and 1.38 (95\% CI: 1.11-1.65) when pooling the adjusted association measures. Long-term former smokers were the main contributors for the higher relapse risk, while the impact of frequency of exposure to e-cigarettes (past, non-daily, daily) was uncertain.

CONCLUSIONS Considering the growing popularity of e-cigarettes among former smokers, our results point to the great potential for an increase in the frequency of relapse to conventional smoking and vaping for those who move to regular use of e-cigarettes.
\end{abstract}

\section{AFFILIATION \\ 1 Health Technology Assessment Center, Division of Populational Research, National Cancer Institute, Rio de Janeiro, Brazil \\ 2 Division of Populational Research, Coordination of Prevention and Surveillance, National Cancer Institute, Rio de Janeiro, Brazil 3 Coordination of Prevention and Surveillance, National Cancer Institute, Rio de Janeiro, Brazil \\ CORRESPONDENCE TO \\ Laura A. Barufaldi. Health \\ Technology Assessment Center, Division of Populational Research, \\ National Cancer Institute, 125 Marquês de Pombal Street, CEP 20230-240, Rio de Janeiro, Brazil. E-mail: laura.barufaldi@inca.gov.br ORCHID ID: https://orcid.org/0000- 0001-9040-4399}

\section{KEYWORDS}

smoking, systematic review, electronic nicotine delivery systems, smoking prevention

Received: 25 August 2020 Revised: 29 January 2021 Accepted: 31 January 2021

\section{INTRODUCTION}

Electronic cigarettes (e-cigarettes) are batterypowered devices in which a liquid, which may contain nicotine, propylene glycol, glycerin, flavors or other chemical additives, is heated and converted into an aerosol for inhalation, commonly called vapor ${ }^{1}$. Following marketing authorization, its popularity has increased in some regions, especially in current smokers, but also among non-smokers and former smokers, driven by greater social acceptance, more positive taste experiences, and fashionable shape, compared to the traditional smoking cigarettes ${ }^{2-5}$. Indeed, in the USA an increase has been observed in the use prevalence among former smokers of e-cigarettes, from $5.3 \%$ in 2015 to $10.9 \%$ in 2018 . A similar trend was found among those who stopped smoking for more than 12 months ago, namely, longterm former smokers in the $\mathrm{UK}^{2,6}$. A study conducted 
in 27 European Union countries, which evaluated more than 26000 individuals aged $\geq 15$ years, observed a prevalence of electronic cigarette use of $20.3 \%$ among current smokers, $4.7 \%$ in ex-smokers and $1.2 \%$ in non-smokers of common cigarettes ${ }^{5}$.

E-cigarettes were introduced to aid smoking cessation and as a less harmful alternative for smokers not willing to quit, by replacing regular cigarettes with devices that mimic their shape while delivering nicotine without inhaling combustion toxins ${ }^{7,8}$. However, the heterogeneity of its liquid components, including additives, solvents and metal nanoparticles that can still produce toxic and carcinogenic substances, and adversely impact health, has raised concerns about the safety of the use of e-cigarettes ${ }^{9-11}$. Besides, e-cigarettes have been the subject of a public health debate on their possibility of undermining efforts for tobacco control. Considering that these devices may be associated with an increased risk of smoking among non-smokers, there is a reduction in quit smoking attempts among dual users and an increased risk of smoking relapse among former smokers $^{2,6,12}$. The latter could be explained by the role of addiction to nicotine as one of the main factors associated with smoking relapse. After smoking cessation, the return to nicotine exposure using e-cigarettes may promote the re-establishment of the dependency cycle ${ }^{13}$. However, it remains relatively unclear how e-cigarette use may affect former combustible cigarette smokers.

This systematic review aimed to identify and summarize longitudinal studies evaluating the risk of smoking relapse using e-cigarettes by former smokers.

\section{METHODS}

The study methodology and eligibility criteria were prespecified and submitted for registration at the PROSPERO database on 18 May 2020. The study report was compliant with the Preferred Reporting Items for Systematic Reviews and Meta-analyses (PRISMA) guidelines (Supplementary file) ${ }^{14}$.

\section{Eligibility criteria}

Longitudinal observational studies that assessed the association between the use of e-cigarettes and smoking relapse among former smokers were eligible for this review. Only studies with humans were included. There was no restriction related to language, date of publication or definitions of former smokers or electronic cigarette users.

\section{Information sources and search strategies}

An initial search for systematic reviews was carried out with terms related to the exposure in the following databases: Medical Literature Analysis and Retrieval System Online (MedLine) via Public MedLine (PubMed), Excerpta Medica Database (EMBASE), Cochrane Library and Latin American and Caribbean Literature in Health Sciences (LILACS). Since no systematic review was identified, a new search for primary studies was carried out on 9 January 2020, and updated on 18 June 2020, in the same databases, except in the Cochrane Library. Besides the terms related to the exposure, we included terms related to the outcome and the population (Supplementary file Table S1).

\section{Selection of studies}

Two independent researchers selected eligible studies, and disagreements were solved by consensus and discussion with a third researcher. After removing duplicate records, the titles and abstracts of all retrieved publications were screened through the Rayyan program, and the eligible publications were assessed by full-text examination ${ }^{15}$. For selection through the reading of the full text, we calculated the kappa coefficient to assess the researchers' correlation.

\section{Data extraction}

The information obtained included characteristics of the eligible studies (author and year of publication, location, study acronym, recruitment, baseline year, length of follow-up, loss to follow-up, covariates, and risk of bias assessment), and the studies' definitions of population, intervention, and outcome. Furthermore, we extracted the total number of participants, the number of relapse cases in exposure and control groups, and the adjusted association estimates, to perform the metaanalysis. Two reviewers independently extracted the data, and inconsistencies were resolved by consensus after data recheck. For one study, missing information was obtained through contact with the authors ${ }^{16}$.

\section{Risk of bias assessment}

The ROBINS-I (Risk Of Bias In Non-randomized Studies of Interventions) tool (cohort studies version) was used to assess the risk of bias of the 
included studies ${ }^{17}$. The bias domains considered in this tool were those that arose: due to confounding, in the selection of participants in the study, in the classification of interventions, due to deviations from intended interventions, due to missing data, in the measurement of outcomes, and in the selection of the reported result. A pair of researchers independently performed this phase, and divergences were discussed and resolved with a third researcher.

\section{Data synthesis}

The characteristics of the included studies were qualitatively described. A meta-analysis was performed to calculate the risk summary estimate and its $95 \%$ confidence interval, using the random effect MantelHaenszel model. The meta-analysis considered three categories of e-cigarette exposure: experimentation or previous use; current occasional or non-daily use; and current regular or daily use. The statistical heterogeneity between the studies was assessed using the $\mathrm{I}^{2}$ test. A meta-analysis was also performed using the association measures adjusted for possible confounding factors, as reported in the studies. Data analysis was performed using the Stata program, version 15.

\section{RESULTS}

A total of 632 references were retrieved from the bibliographical databases. After removing 149 duplicates, 483 titles and abstracts were screened, and 469 publications not related to the study question were excluded. After full-text reading of 14 articles (Kappa concordance coefficient $=0.69$, therefore strong), six met the eligibility criteria and were included in the qualitative synthesis (Figure 1).

Table 1 describes the characteristics of the six studies. Four studies were conducted in the USA with data from the PATH (Population Assessment of Tobacco and Health Study), a national cohort study with noninstitutionalized adults ${ }^{18-21}$. One study evaluated a national sample from the general population of smokers, former smokers and vapers aged $\geq 18$ years in the UK, and one study included adults aged 18-69 years from a

\section{Figure 1. Flowchart of studies selection}
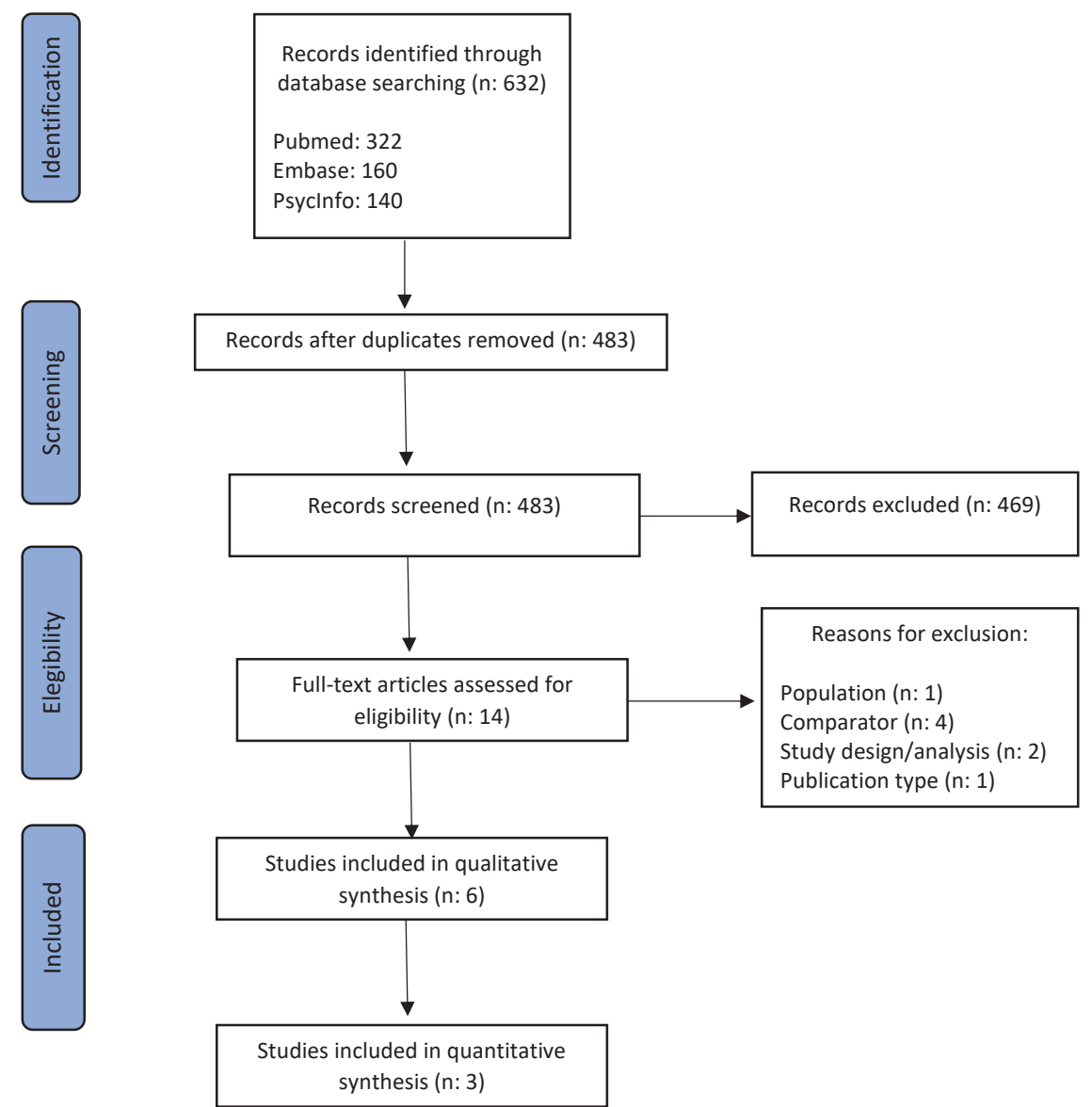
compulsory health insurance scheme in France, which covers about $85 \%$ of the population ${ }^{16,22}$.

The baseline evaluation of former smokers, users and non-users of e-cigarettes, occurred from 2013 to 2016 , and the follow-up ranged from 12 to 36 months. The frequency of relapse was assessed at the end of the follow-up, after accounting for $1 \%$ to $48.4 \%$ of participant loss. All studies estimated the risk of relapse adjusted for covariates, including age, gender, income, and educational level. Brose et al. ${ }^{22}$ included further information on nicotine replacement therapy and cessation duration among former smokers, while Everard et al. ${ }^{18}$ and Gomajee et al. ${ }^{16}$ included the greatest number of covariables in the model.

According to the risk of bias assessment, two studies were classified as low risk ${ }^{16,19}$, two moderate ${ }^{18,22}$ and two high risk ${ }^{20,21}$. The risk of bias was mainly affected in domains related to the adjustment of confounding variables, and the loss of follow-up or failure to consider it in the analysis.

The definitions of population, intervention and outcome adopted in the studies are described in Table 2. Regarding population, studies that have used data from the PATH study defined former smokers as individuals who reported consuming $\geq 100$ combustible cigarettes in their lifetime, and no use at baseline ${ }^{19,21}$ or at least five years before the baseline ${ }^{20}$. Everard et al. ${ }^{18}$ further excluded individuals who consumed other tobacco products at baseline, including cessation therapy with

Table 1. Description of the characteristics of the studies

\begin{tabular}{|c|c|c|c|c|c|c|c|c|}
\hline $\begin{array}{l}\text { Author, } \\
\text { year }\end{array}$ & Location & Acronym & Recruitment & $\begin{array}{c}\text { Baseline } \\
\text { year }\end{array}$ & $\begin{array}{l}\text { Follow-up } \\
\text { (months) }\end{array}$ & $\begin{array}{l}\text { Loss at } \\
\text { follow-up }\end{array}$ & Covariates $^{a}$ & $\begin{array}{c}\text { Risk of } \\
\text { bias }\end{array}$ \\
\hline $\begin{array}{l}\text { Everard } \\
\text { et al. }{ }^{18} \\
2020\end{array}$ & USA & PATH & $\begin{array}{l}\text { National cohort with } \\
\text { non-institutionalized } \\
\text { adults ( } \geq 18 \text { years old) }\end{array}$ & 2013-2014 & 36 & $\mathrm{NI}$ & $\begin{array}{l}\text { Age, sex, race/ethnicity, } \\
\text { education, family income, } \\
\text { use of other tobacco } \\
\text { products, internalizing/ } \\
\text { externalizing/substance } \\
\text { use problems and past } \\
\text { cigarette use behavior }\end{array}$ & Moderate \\
\hline $\begin{array}{l}\text { McMillen } \\
\text { et al. } .^{20} \\
2019\end{array}$ & USA & PATH & $\begin{array}{l}\text { National cohort with } \\
\text { non-institutionalized } \\
\text { adults ( } \geq 18 \text { years old) }\end{array}$ & 2013-2014 & 12 & $16.9 \%$ & $\begin{array}{l}\text { Age, sex, race/ethnicity, } \\
\text { education, household } \\
\text { smoking rules and } \\
\text { cohabitation with smokers }\end{array}$ & High \\
\hline $\begin{array}{l}\text { Verplaetse } \\
\text { et al..21 } \\
2019\end{array}$ & USA & PATH & $\begin{array}{l}\text { National cohort with } \\
\text { non-institutionalized } \\
\text { adults ( } \geq 18 \text { years old) }\end{array}$ & 2013-2014 & 12 & $\mathrm{NI}$ & $\begin{array}{l}\text { Age, sex, race/ethnicity } \\
\text { and education }\end{array}$ & High \\
\hline $\begin{array}{l}\text { Brose } \\
\text { et al. }{ }^{22} \\
2019^{*}\end{array}$ & UK & - & $\begin{array}{l}\text { National general } \\
\text { population sample } \\
\text { of smokers, former } \\
\text { smokers and vapers } \\
\text { ( } \geq 18 \text { years old) }\end{array}$ & 2016 & 16 & $48.4 \%$ & $\begin{array}{l}\text { Age, sex, annual } \\
\text { income, duration of } \\
\text { cessation, use of NRT } \\
\text { and characteristics of } \\
\text { e-cigarette use }\end{array}$ & Moderate \\
\hline $\begin{array}{l}\text { Dai et al. }{ }^{19} \\
2019^{*}\end{array}$ & USA & PATH & $\begin{array}{l}\text { National cohort with } \\
\text { non-institutionalized } \\
\text { adults ( } \geq 18 \text { years old) }\end{array}$ & 2013-2014 & 12 & $16.9 \%$ & $\begin{array}{l}\text { Age, sex, race/ethnicity, } \\
\text { education, family } \\
\text { income, health insurance } \\
\text { and region }\end{array}$ & Low \\
\hline $\begin{array}{l}\text { Gomajee } \\
\text { et al. }{ }^{16} \\
2019^{*}\end{array}$ & France & CONSTANCES & $\begin{array}{l}\text { National sample } \\
\text { of adults (18-69 } \\
\text { years old) from a } \\
\text { compulsory health } \\
\text { insurance ( } 85 \% \text { of } \\
\text { population coverage) }\end{array}$ & 2015 & 22 (mean) & $1.0 \%$ & $\begin{array}{l}\text { Age, sex, marital status, } \\
\text { education, income, use } \\
\text { of alcohol, number of } \\
\text { cigarettes smoked at } \\
\text { baseline, number of packs/ } \\
\text { year, duration of previous } \\
\text { attempts to quit and } \\
\text { comorbidities (depression, } \\
\text { respiratory disorders) }\end{array}$ & Low \\
\hline
\end{tabular}


e-cigarettes. Dai et al. ${ }^{19}$ and Everard et al. ${ }^{18}$ classified the participants as 'recent former smokers' (smoking cessation in the last 12 months) or 'long-term former smokers' (smoking cessation for more than 12 months). Brose et al. ${ }^{22}$ defined former smokers as individuals who stopped smoking for at least two months at baseline, while Gomajee et al. ${ }^{16}$ as those who reported smoking cessation since 2010 (within five years from the study baseline). At the end of the follow-up, the sample size ranged from 374 to 4094 former smokers with a mean age $43-48$ years. The female proportion was between $45 \%$ and $53 \%$.

Most studies have classified exposure to e-cigarettes in at least two categories: experimentation or past use, and current use. Brose et al. ${ }^{22}$ and Dai et al. ${ }^{19}$ further classified current use in regular or daily use, and occasional or nondaily use. Everard et al. ${ }^{18}$ considered using any electronic nicotine delivery system (e-cigarettes, e-cigars, e-pipes, and e-hookah) in the previous 12 months. In the study by Gomajee et al. ${ }^{16}$, the exposure was only current daily use, while in the study by Verplaetse et al. ${ }^{21}$, it was current daily and non-daily use.

The definition of the outcome of smoking relapse also varied between the studies as follows: current use of combustible cigarettes (daily or not) or use in the last 30 days in studies derived from PATH ${ }^{18-}$ ${ }^{21}$, use of combustible cigarettes, including cases of lapses or relapse to smoking in the study by Brose et al. ${ }^{22}$, and daily use of combustible cigarettes in the study by Gomajee et al. ${ }^{16}$.

For the meta-analysis, data from three trials were used ${ }^{16,19,22}$. Everard et al. ${ }^{18}$, McMillen et al. ${ }^{20}$ and Verplaetse et al. ${ }^{21}$ were excluded from the quantitative analysis because they totally or partially shared the study participants by Dai et al. ${ }^{19}$. This study was chosen since it has a larger sample size and better classification in the risk of bias assessment.

The meta-analysis showed a twice higher risk of smoking relapse $(\mathrm{RR}=2.03$; 95\% CI: 1.39-2.96) for former smoker users than non-users of e-cigarettes. The statistical heterogeneity between the studies was high $\left(I^{2}=92.1 \%\right.$; $\left.<0.001\right)$ (Figure 2$)$.

Figure 2. Meta-analysis of the risk of smoking relapse associated with electronic cigarette use (experimentation or past use, current occasional use and current regular use)

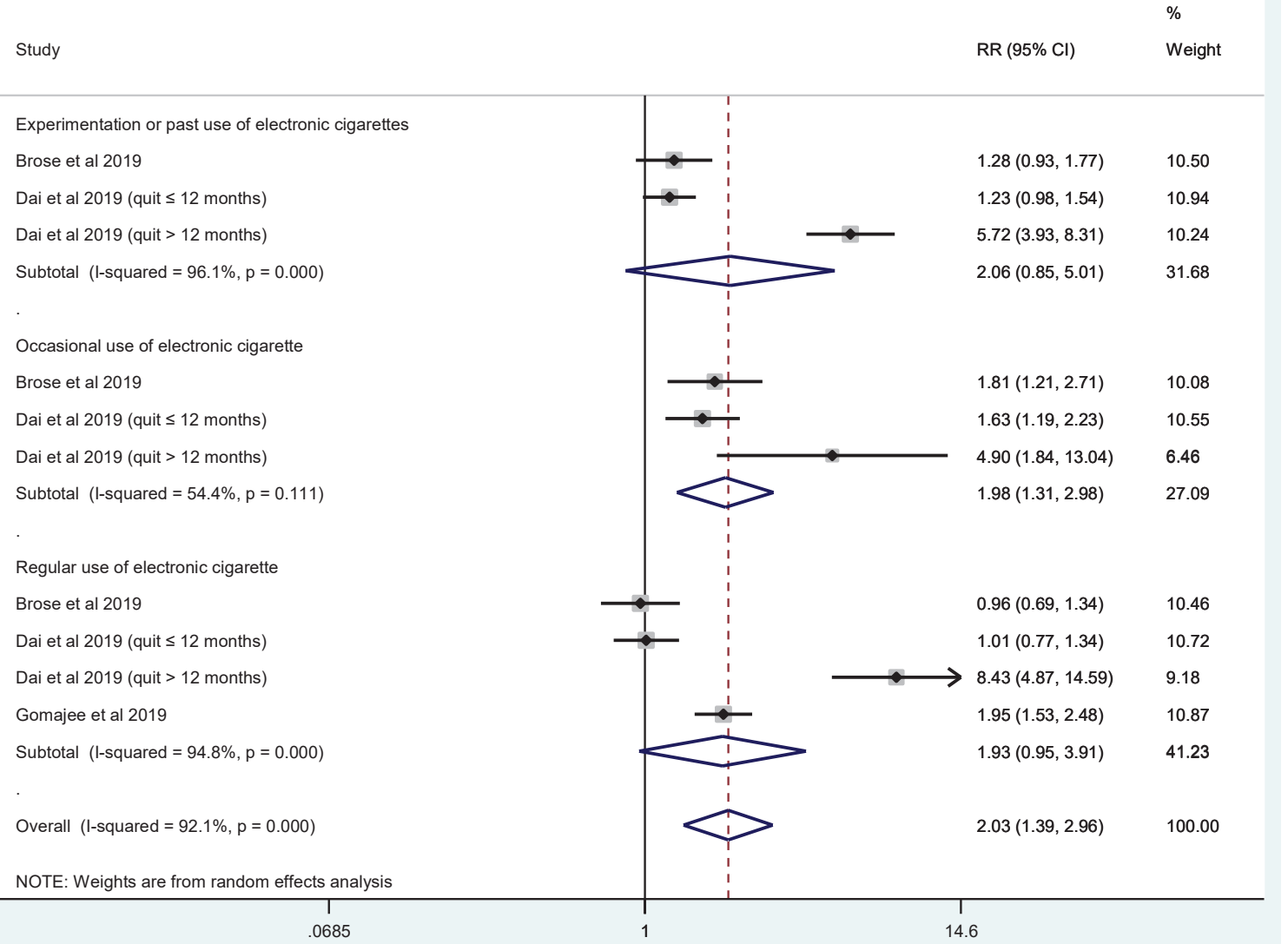


For the subgroups of exposure to e-cigarettes, the risk of smoking relapse was not statistically significant among former smokers who tried or used an electronic cigarette in the past $(\mathrm{RR}=2.06 ; 95 \%$ CI: 0.85-5.01), and among those who regularly use the device $(\mathrm{RR}=1.93 ; 95 \% \mathrm{CI}: 0.95-3.91)$. The heterogeneity between the studies was high, partly due to the result among long-term former smokers of the study by Dai et al. ${ }^{19}$ in which the risk of smoking relapse was significantly greater either in the past-use group ( $\mathrm{RR}=5.72$; 95\% CI: $3.93-8.31$ ) and in the regular-use group $(\mathrm{RR}=8.43 ; 95 \% \mathrm{CI}$ : 4.87-14.59). On the other hand, for occasional users of e-cigarettes, the risk of smoking relapse was approximately twice higher compared to nonusers $(\mathrm{RR}=1.98 ; 95 \% \mathrm{CI}$ : $1.31-2.98)$, with low heterogeneity between the studies $\left(\mathrm{I}^{2}=54.4 \%\right.$; $\mathrm{p}=0.111)$.

The meta-analysis of the adjusted association measures of the primary studies demonstrated a smoking relapse risk of 1.38 (95\% CI: $1.11-$
1.65) for former smoker users of e-cigarettes, without heterogeneity found between the studies (Supplementary file Figure S1). However, when we evaluated the subgroups of exposure, the risk of smoking relapse associated with e-cigarette use remained higher, but without statistical significance. For past use of e-cigarettes, the risk of relapse was 1.40 (95\% CI: 0.94-1.87; $\left.\mathrm{I}^{2}=0.2 \% ; \mathrm{p}=0.367\right)$, while 1.97 (95\% CI: $0.56-3.37 ; \mathrm{I}^{2}=0 \%$; $\mathrm{p}=0.928$ ) for occasional use, and 1.32 (95\% CI: 0.83-1.80; $\left.\mathrm{I}^{2}=40.4 \% ; \mathrm{p}=0.169\right)$ for regular use.

Although the study of Everard et al. ${ }^{18}$ shares part of the population from the study of Dai et al. ${ }^{19}$, the authors sought to estimate the undiluted effect of electronic nicotine delivery systems on smoking relapse by only including individuals with abstinence from all tobacco products at baseline. In addition, they considered the use of any electronic nicotine delivery system and evaluated the outcome in a longer follow-up (36 months). In this study, the adjusted risk of smoking relapse was 2.98 (95\% CI:

\section{Table 2. Description of the population, intervention and outcome considered in the studies}

\begin{tabular}{|c|c|c|c|c|c|c|}
\hline \multirow[t]{2}{*}{ Study } & \multicolumn{3}{|l|}{ Population } & \multicolumn{3}{|c|}{ Exposure groups } \\
\hline & Former smokers & $\mathbf{N}^{a}$ & Age (years) & Female & E-cigarette use & Smoking relapse \\
\hline $\begin{array}{l}\text { Everard } \\
\text { et al. }{ }^{18} \\
2020\end{array}$ & $\begin{array}{l}\text { Individuals who ever smoked a cigarette or have } \\
\text { smoked } \geq 100 \text { cigarettes in lifetime, not using } \\
\text { any tobacco products at baseline. Classified as } \\
\text { 'recent' (interruption } \leq 12 \text { months) or 'long- } \\
\text { term' smokers (interruption }>12 \text { months) }\end{array}$ & 2273 & $\mathrm{NI}$ & $51.8 \%$ & $\begin{array}{l}\text { Past 12-month use } \\
\text { of any ENDS: } \\
\text { e-cigarettes, } \\
\text { e-cigars, } \\
\text { e-pipes, and } \\
\text { e-hookah }\end{array}$ & $\begin{array}{l}\text { Current daily } \\
\text { or non-daily } \\
\text { cigarettes smoking }\end{array}$ \\
\hline $\begin{array}{l}\text { McMillen } \\
\text { et al. } .^{20} \\
2019\end{array}$ & $\begin{array}{l}\text { Individuals who have smoked } \geq 100 \text { cigarettes in } \\
\text { lifetime, and have quit smoking } 5 \text { years before } \\
\text { the study baseline (distant former smokers) }\end{array}$ & 2322 & $\mathrm{NI}$ & $45.6 \%$ & $\begin{array}{l}\text { Ever use (except in } \\
\text { last } 30 \text { days) } \\
\text { Past } 30 \text {-day use }\end{array}$ & $\begin{array}{l}\text { Past } 30 \text {-day } \\
\text { cigarettes smoking }\end{array}$ \\
\hline $\begin{array}{l}\text { Verplaetse } \\
\text { et al..21 } \\
2019\end{array}$ & $\begin{array}{l}\text { Individuals who have smoked } \geq 100 \text { cigarettes } \\
\text { in lifetime, and were not using cigarettes at } \\
\text { baseline }\end{array}$ & $\mathrm{NI}$ & $\mathrm{NI}$ & $\mathrm{NI}$ & $\begin{array}{l}\text { Current daily and } \\
\text { non-daily use }\end{array}$ & $\begin{array}{l}\text { Current daily } \\
\text { or non-daily } \\
\text { cigarette smoking }\end{array}$ \\
\hline $\begin{array}{l}\text { Brose } \\
\text { et al. }{ }^{22} \\
2019^{*}\end{array}$ & $\begin{array}{l}\text { Smokers who stopped smoking for at least } 2 \\
\text { months from the study baseline }\end{array}$ & 374 & $\begin{array}{l}\text { Mean } \pm \text { SD } \\
48.1 \pm 15.3\end{array}$ & $45.7 \%$ & $\begin{array}{l}\text { Past/ever use } \\
\text { Current } \\
\text { non-daily use } \\
\text { Current daily use }\end{array}$ & $\begin{array}{l}\text { Lapses or relapsed } \\
\text { to cigarettes } \\
\text { smoking during } \\
\text { follow-up }\end{array}$ \\
\hline $\begin{array}{l}\text { Dai et al. }{ }^{19} \\
2019^{*}\end{array}$ & $\begin{array}{l}\text { Individuals who have smoked } \geq 100 \text { cigarettes } \\
\text { in lifetime, not using any tobacco products at } \\
\text { baseline. Classified as 'recent' (interruption } \leq 12 \\
\text { months) or 'long-term' smokers (interruption } \\
>12 \text { months) }\end{array}$ & 4094 & $\mathrm{NI}$ & $\begin{array}{l}\text { Recent } \\
53.1 \% \\
\text { Long-term } \\
45.9 \%\end{array}$ & $\begin{array}{l}\text { Previous use } \\
\text { Current occasional } \\
\text { use } \\
\text { Current regular use }\end{array}$ & $\begin{array}{l}\text { Current daily } \\
\text { or non-daily } \\
\text { cigarette smoking }\end{array}$ \\
\hline $\begin{array}{l}\text { Gomajee } \\
\text { et al. }{ }^{16} \\
2019^{*}\end{array}$ & $\begin{array}{l}\text { Smokers who have quit smoking from } 2010 \\
\text { (year that e-cigarette was commercially } \\
\text { introduced in France) }\end{array}$ & 2025 & $\begin{array}{l}\text { Mean } \pm \text { SD } \\
43.6 \pm 12.1\end{array}$ & $49.6 \%$ & $\begin{array}{l}\text { Current regular } \\
\text { (daily) use }\end{array}$ & $\begin{array}{l}\text { Use of } \geq 1 \\
\text { cigarettes/day } \\
\text { during follow-up }\end{array}$ \\
\hline
\end{tabular}

ENDS: electronic nicotine delivery system. SD: standard deviation. NI: not informed. ${ }^{*}$ Included in the quantitative synthesis (meta-analysis). a Number of participants at the end of the study follow-up. 
1.93-4.60) for users compared to non-users of these electronic devices, 1.63 (95\% CI: 1.04-2.53) in recent former smokers and 3.79 (95\% CI: 1.75-8.2) in long-term former smokers ${ }^{18}$.

\section{DISCUSSION}

The results of this systematic review with metaanalysis of longitudinal studies point to an increased risk of relapse to conventional smoking associated with the use of electronic cigarettes in former smokers. The association was found both in the raw and adjusted data analysis.

Smoking remains the leading preventable cause of illness and premature death in many countries $^{23}$. Although quit attempts are widespread among smokers, the majority are unsuccessful. In a populational cohort survey conducted in the USA, UK, Canada and Australia, $82 \%$ of smokers reported having made quit attempts in their lifetime, with an average of 2.1 attempts, and around $40 \%$ reporting recent attempts in the year before recruitment. However, about one-third of smokers have stopped smoking for more than six months, and only $15.5 \%$ of the sample retained through the whole follow-up had succeeded in staying quit for 12 months $^{24}$. Therefore, efforts have been made to achieve prolonged cessation by means of several strategies proposed to help prevent relapse, such as extended pharmacological therapies and behavioral interventions, in which former smokers learn to identify and deal with high risk situations ${ }^{25}$.

In this context, the introduction of e-cigarettes in the global market seems to function oppositely. The results of this systematic review demonstrate the use of e-cigarettes as a risk factor for smoking relapse. The meta-analysis of longitudinal studies estimated risk of relapse twice higher among former smokers who use e-cigarettes than among non-users. When evaluating subgroups that might explain this association, non-daily exposure to e-cigarettes was shown particularly important from the summarized raw data. Total abstinence from tobacco products, and the consequent interruption of the nicotine dependence cycle, is the basis of smoking cessation treatment. Similar to combustible cigarettes, but unlike most nicotine replacement therapies, e-cigarettes can provide a pleasurable experience to the user by inhalation of tasteful and sensory stimulating substances ${ }^{3,26}$. Electronic cigarettes can be classified in more than one generation. The first is similar to a cigarette form and without a button to press before inhalation. The advanced generation has a larger high-power battery and a button to press before inhalation. A possible factor that may influence the choice is the delivery of nicotine ${ }^{27}$. Recent studies have shown that advanced generation devices can deliver nicotine more efficiently ${ }^{27-29}$ and are perceived as providing greater satisfaction and reduced desire ${ }^{27}$. In addition, other factors such as the design characteristics or a variety of liquid nicotine flavor options may influence the user's choice.

Therefore, the current but not daily chemical and behavioral exposure to e-cigarettes can accentuate the former smokers' vulnerability to smoking relapse. The low consumption of nicotine through irregular e-cigarette use fails to sufficiently protect the former smokers against the increased risk of relapse $\mathrm{e}^{13,19}$.

Although past use or current regular use of e-cigarettes equally demonstrate an increased risk of smoking relapse in our study, the result was not statistically significant. Amid uncertainties, it is possible that experimenting with e-cigarettes, without a progression towards sustainable use, is not enough for former smokers to recover their smoking habit, while its daily use supplies the need for nicotine especially among those with a higher degree of dependence. Indeed, a multi-center cross-sectional study, comparing the indicators of nicotine dependence and relapse between former smoker non-users and daily users of e-cigarettes, demonstrated higher levels of addiction, before and after cessation, in those who daily use nicotine through e-cigarettes. Moreover, these individuals reported greater confidence in staying abstinent from conventional cigarettes, despite having a similar desire to smoke ${ }^{30}$. Thus, by replacing nicotine delivery products, highly dependent former smokers could prevent smoking relapse, but may start using e-cigarettes.

In this meta-analysis, the trend of an increased risk of smoking relapse among past and regular users of e-cigarettes was mainly due to the results obtained in the population of long-term former smokers from the study of Dai et al. ${ }^{19}$. Former smokers who 
had quit smoking more than 12 months ago and then tried or used e-cigarettes had a significantly increased risk of smoking relapse compared to those who did not use the electronic device ${ }^{19}$. In general, the smokers who seek to stop smoking, in an assisted or unassisted way, have higher relapse risk in the first year following cessation, especially in the first three months. However, this risk progressively decreases throughout the period of abstinence ${ }^{31-33}$. In a population-based representative prospective study in the USA, for example, the smoking relapse rate among 12 months or less abstinent individuals was greater than $50 \%$, about $65 \%$ in the first three months, and stabilized around $10 \%$ after 30 years of abstinence ${ }^{33}$. Therefore, e-cigarettes seem to have a mitigated contribution amid already high probability of relapse in the first year after cessation. At the same time, it tends to perpetuate the vulnerability to relapse that would usually be reduced after prolonged abstinence.

In the meta-analysis, of association measures studies, the summary estimate remained significant, showing an adjusted risk of smoking relapse $38 \%$ higher for e-cigarettes users. However, the risk estimates by subgroups of e-cigarette exposure frequency lost their statistical significance due to broader confidence intervals in these smaller subgroups. The exception was seen again among long-term former smokers, for whom the risk of relapse remained significantly increased in past and regular use of e-cigarettes ${ }^{19}$. Additional factors independently associated with smoking relapse demonstrated by these studies were young age, ethnicity (non-Hispanic Blacks), use of other tobacco products and shorter abstinence duration ${ }^{19,22}$. Although not included in the meta-analysis, the study by Everard et al. ${ }^{18}$ also showed a higher risk of relapse among long-term former smokers likely enhanced by the use of an electronic nicotine delivery system, demonstrated by the longer followup capable of capturing individuals relapsing after an extended abstinence ${ }^{18}$.

\section{Strengths and limitations}

There are some limitations in this review. The retrieval of only a few studies has impaired exploratory analyses in smaller subgroups and precluded a publication bias analysis. The high statistical heterogeneity of raw data was probably due to the differences in studies' definitions, such as for the population (former smokers) and the outcome (smoking relapse). In the risk-adjusted meta-analysis, we considered a variety of covariates in the studies. Although most studies have included at least sex, age, socioeconomic status and a variable related to smoking, more uniform information about abstinence duration, degree of dependence and e-cigarette features could increase our results consistency. The meta-analysis findings should be considered with caution, considering the small number of studies and the high heterogeneity.

On the other hand, our bibliography research indicates that it is the first systematic review evaluating the association between the use of e-cigarettes and smoking relapse. The results of this study may support global smoking control policies, such as maintaining the sale prohibition of electronic cigarettes in countries where it is not allowed, such as Brazil. Besides, this information can be included in individual strategies for former smokers' care to prevent smoking relapse. Additional favorable points of this review are that many former smokers were evaluated, despite the few included studies, and the inclusion of only longitudinal studies. The smoking abstinence at baseline shows that exposure to e-cigarettes occurred before smoking relapse, ensuring the association's temporality.

\section{CONCLUSIONS}

There is an increased risk of smoking relapse among users of e-cigarettes, which may be explained by long-term former smokers. The main uncertainty is whether there is a difference in the risk according to e-cigarette exposure frequency. The popularity of e-cigarettes among former smokers is growing. In this scenario, our results point to their great potential to increase the frequency of relapse to conventional smoking, besides moving to the regular use of e-cigarettes.

\section{REFERENCES}

1. World Health Organization. WHO Report on the global tobacco epidemic, 2019: Offer help to quit tobacco use. World Health Organization; 2019. Accessed June 20, 2020. https://apps.who.int/iris/bitstream/hand le/10665/326043/9789241516204-eng.pdf?ua=1\&ua=1

2. McNeill A, Brose LS, Calder R, Bauld L, Robson D. Evidence review of e-cigarettes and heated tobacco 
products 2018: A report commissioned by Public Health England. Public Health England; 2018. Accessed June 20, 2020. https://assets.publishing.service.gov.uk/ government/uploads/system/uploads/attachment_data/ file/684963/Evidence_review_of_e-cigarettes_and_ heated_tobacco_products_2018.pdf

3. Romijnders K, van Osch L, de Vries H, Talhout R. Perceptions and reasons regarding e-cigarette use among users and non-users: a narrative literature review. Int J Environ Res Public Health. 2018;15(6):11-22. doi:10.3390/ijerph15061190

4. McMillen RC, Gottlieb MA, Whitmore SRM, Winickoff JP, Klein JD. Trends in Electronic Cigarette Use Among U.S. Adults: Use is Increasing in Both Smokers and Nonsmokers. Nicotine Tob Res. 2015;17(10):1195-1202. doi:10.1093/ntr/ntu213

5. Vardavas CI, Filippidis FT, Agaku IT. Determinants and prevalence of e-cigarette use throughout the European Union: a secondary analysis of 26566 youth and adults from 27 Countries. Tob Control. 2015;24(5):442-448. doi:10.1136/tobaccocontrol-2013-051394

6. Kock L, Shahab L, West R, Brown J. E-cigarette use in England 2014-17 as a function of socio-economic profile. Addiction. 2018;114(2):294-303. doi:10.1111/add.14446

7. Siegel MB, Tanwar KL, Wood KS. Electronic Cigarettes As a Smoking-Cessation Tool: Results from an online survey. Am J Prev Med. 2011;40(4):472-475. doi:10.1016/j.amepre.2010.12.006

8. Goniewicz ML, Knysak J, Gawron M, Kosmider L, et al. Levels of selected carcinogens and toxicants in vapour from electronic cigarettes. Tob Control. 2014;23(2):133139. doi:10.1136/tobaccocontrol-2012-050859

9. Cao DJ, Aldy K, Hsu S, McGetrick M, Verbeck G, De Silva I, Feng SY. Review of Health Consequences of Electronic Cigarettes and the Outbreak of Electronic Cigarette, or Vaping, Product Use-Associated Lung Injury. J Med Toxicol. 2020;16(3):295-310. doi:10.1007/s13181-020-00772-w

10. McRobbie H, Phillips A, Goniewicz ML, Smith KM, Knight-West O, Przulj D, Hajek P. Effects of Switching to Electronic Cigarettes with and without Concurrent Smoking on Exposure to Nicotine, Carbon Monoxide, and Acrolein. Cancer Prev Res (Phila). 2015;8(9):873-878. doi:10.1158/1940-6207.CAPR-15-0058

11. O'Connell G, Graff DW, D'Ruiz CD. Reductions in biomarkers of exposure (BoE) to harmful or potentially harmful constituents (HPHCs) following partial or complete substitution of cigarettes with electronic cigarettes in adult smokers. Toxicol Mech Methods. 2016;26(6):453464. doi:10.1080/15376516.2016.1196282

12. Jackson SE, Shahab L, West R, Brown J. Associations between dual use of e-cigarettes and smoking cessation: A prospective study of smokers in England. Addict Behav. 2020;103:106230. doi:10.1016/j.addbeh.2019.106230

13. Vangeli E, Stapleton J, Smit ES, Borland R, West R. Predictors of attempts to stop smoking and their success in adult general population samples: a systematic review. Addiction. 2011;106(12):2110-2121. doi:10.1111/j.13600443.2011.03565.x

14. Prisma. The PRISMA Statement. 2009. Accessed June 20, 2020. http://prisma-statement.org/PRISMAStatement/ PRISMAStatement

15. Ouzzani M, Hammady H, Fedorowicz Z, Elmagarmid A. Rayyan-a web and mobile app for systematic reviews. Syst Rev. 2016;5(1):210. doi:10.1186/s13643-016-0384-4

16. Gomajee R, El-Khoury F, Goldberg M, et al. Association Between Electronic Cigarette Use and Smoking Reduction in France. JAMA Intern Med. 2019;179(9):1193-1200. doi:10.1001/jamainternmed.2019.1483

17. Sterne JA, Hernán MA, Reeves BC et al. ROBINS-I: a tool for assessing risk of bias in non-randomised studies of interventions. BMJ. 2016;355:i4919. doi:10.1136/bmj.i4919

18. Everard CD, Silveira ML, Kimmel HL, Marshall D, Blanco C, Compton WM. Association of Electronic Nicotine Delivery System Use With Cigarette Smoking Relapse Among Former Smokers in the United States. JAMA Netw Open. 2020;3(6):e204813. doi:10.1001/jamanetworkopen.2020.4813

19. Dai H, Leventhal AM. Association of electronic cigarette vaping and subsequent smoking relapse among former smokers. Drug Alcohol Depend. 2019;199:10-17. doi:10.1016/j.drugalcdep.2019.01.043

20. McMillen R, Klein JD, Wilson K, Winickoff JP, Tanski S. E-Cigarette Use and Future Cigarette Initiation Among Never Smokers and Relapse Among Former Smokers in the PATH Study. Public Health Rep. 2019;134(5):528536. doi:10.1177/0033354919864369.

21. Borland R, Partos TR, Yong HH, Cummings KM, Hyland A. How much unsuccessful quitting activity is going on among adult smokers? Data from the International Tobacco Control Four Country cohort survey. Addiction. 2012;107(3):673682. doi:10.1111/j.1360-0443.2011.03685.x

22. Brose LS, Bowen J, McNeill A, Partos TR. Associations between vaping and relapse to smoking: preliminary findings from a longitudinal survey in the UK. Harm Reduct J. 2019;16(1):76. doi:10.1186/s12954-019-0344-0

23. GBD 2015 Tobacco Collaborators. Smoking prevalence and attributable disease burden in 195 countries and territories, 1990-2015: a systematic analysis from the Global Burden of Disease Study 2015. Lancet. 2017;389(10082):18851906. doi:10.1016/S0140-6736(17)30819-X

24. Borland R, Partos TR, Yong HH, Cummings KM, Hyland A. How much unsuccessful quitting activity is going on among adult smokers? Data from the International Tobacco Control Four Country cohort survey. Addiction. 2012;107(3):673682. doi:10.1111/j.1360-0443.2011.03685.x

25. Livingstone-Banks J, Norris E, Hartmann-Boyce J, West R, Jarvis M, Chubb E, Hajek P. Relapse prevention interventions for smoking cessation. Cochrane Database Syst Rev. 2019;2019(10):CD003999. doi:10.1002/14651858.CD003999.pub6. 
26. Breland A, Soule E, Lopez A, Ramôa C, El-Hellani A, Eissenberg T. Electronic cigarettes: what are they and what do they do? Ann N Y Acad Sci. 2017;1394(1):5-30. doi:10.1111/nyas.12977

27. Farsalinos KE, Spyrou A, Stefopoulos C, et al. Nicotine absorption from electronic cigarette use: comparison between experienced consumers (vapers) and naïve users (smokers). Sci Rep. 2015;5(1):11269. doi:10.1038/srep11269

28. Vansickel AR, Eissenberg T. Electronic cigarettes: effective nicotine delivery after acute administration. Nicotine Tob Res. 2013;15(1):267-270. doi:10.1093/ntr/ntr316

29. Eissenberg T. Electronic nicotine delivery devices: ineffective nicotine delivery and craving suppression after acute administration. Tob Control. 2010;19(1):8788. doi:10.1136/tc.2009.033498

30. McNeill A, Driezen P, Hitchman SC, Cummings KM, Fong GT, Borland R. Indicators of cigarette smoking dependence and relapse in former smokers who vape compared with those who do not: findings from the 2016 International Tobacco Control Four Country Smoking and Vaping Survey. Addiction. 2019;114(Suppl 1):49-60. doi:10.1111/add.14722

31. Herd N, Borland R, Hyland A. Predictors of smoking relapse by duration of abstinence: findings from the International Tobacco Control (ITC) Four Country Survey. Addiction. 2009;104(12):2088-99. doi:10.1111/j.1360-0443.2009.02732.x

32. Powell J, Dawkins L, West R, Powell J, Pickering A. Relapse to smoking during unaided cessation: clinical, cognitive and motivational predictors. Psychopharmacology (Berl). 2010;212(4):537-549. doi:10.1007/s00213-010-1975-8

33. García-Rodríguez O, Secades-Villa R, Flórez-Salamanca L, Okuda M, Liu SM, Blanco C. Probability and predictors of relapse to smoking: results of the National Epidemiologic Survey on Alcohol and Related Conditions (NESARC). Drug Alcohol Depend. 2013;132(3):479-485. doi:10.1016/j.drugalcdep.2013.03.008
CONFLICTS OF INTEREST

The authors have completed and submitted the ICMJE Form for Disclosure of Potential Conflicts of Interest and none was reported.

\section{FUNDING}

R.C.R. de Albuquerque, A. Nascimento and R.D. Chança received a scholarship from the Institutional Development Program of the National Cancer Institute José Alencar Gomes da Silva (INCA). This work was supported by the Foundation for Research Support in the State of Rio de Janeiro (FAPERJ) through the Project Health Research Network of State of Rio de Janeiro (E-26/010.002428/2019).

ETHICAL APPROVAL AND INFORMED CONSENT

Ethical approval and informed consent were not required for this study.

PROVENANCE AND PEER REVIEW

Not commissioned; externally peer reviewed. 